\title{
Heidegger. Denker in die skaduwee van die Nihilisme
}

\author{
M J SCHOEMAN
}

Wanner 'n mens kyk na die huidige stand van die filosofie, bemerk jy 'n warboel van uiteenlopende beskouings oor wat nou eintlik die taak van die filosofie is. Daar heers groot onsekerheid oor waarin die bestaansreg van die filosofie vandag setel. Die filosofie het vir die filosofie sy grootste en dringendste probleem geword, en dit is die geval omdat die filosofie homself vandag nie langer kan of wil verstaan as voortsetting van sy tradisie nie. Anders gestel: Die filosofie, in soverre as wat hy hom verstaan as metafisika (dit wil sê as voortsetting van ' $n$ bepaalde denkvorm wat by Plato en Aristoteles sy beslag gekry het) het vandag voor 'n dooiepunt te staan gekom.

Waarom kan die filosofie homself nie meer verstaan as voortsetting van die metafisiese tradisie nie? Wat word bedoel met die stelling dat die metafisika voor 'n dooiepunt te staan gekom het? Die antwoord op hierdie vrae kan gevind word in 'n eksplisitering van dáárdie grondverskynsel waarin die bankrotskap van die metafisiese tradisie finaal aan die lig gekom het: die nihilisme. Dit was Heidegger wat vir die eerste maal gewys het op die innerlike verband tussen nihilisme en metafisika. Die nihilisme soos wat dit in die filosofie van Nietzsche vir die eerste maal duidelik tot spreke gebring is, dui nie op 'n insinking of verval van die metafisiese tradisie nie. Veel eerder is dit die logiese voleinding van 'n tendens wat die metafisika reeds by sy aanvang in hom omgedra het. Heidegger huiwer nie om te stel dat die metafisika sélf die grond van die nihilisme is nie. ${ }^{1}$ Met Nietzsche het die metafisika net die punt bereik waarin hy sy ware kleur begin wys het.

Waarin bestaan die nihilisme nou eintlik, en waarop berus die stelling dat die metafisika reeds sedert sy aanvang onherroeplik afstuur op nihilisme? Bekend is die omskrywing wat Nietzsche van die nihilisme gee aan die begin van sy "Wille zur Macht": "Was bedeutet Nihilismus? - Dass die obersten Werte sich entwerten. Es fehlt das Ziel; es fehlt die Antwort auf das Warum?". Wanneer die nihilisme dui op 'n verlies of ineenstorting van waardes, kan daar met reg gevra word wat dit met die metafisika uit te waai het. Was die metafisika dan nie daardie gestrenge denkdissipline waarin dit suiwer gegaan het om die vraag na die Syn van die syndes nie? Of is dit miskien die geval dat daar agter die (suiwer teoretiese) soeke na waarheid in die beoefening van die metafisika eintlik ' $n$ (praktiese) soeke na waardes skuilgegaan het? Heidegger is daarvan oortuig dat laasgenoemde wel die geval is. 
Die metafisika het minstens vanaf Plato die Syn uitgelê in terme van ' $n$ hoogste waarde. Daarmee het die vraag na die Syn sélf in die agtergrond verdwyn, en het die metafisika verval in wat Heidegger "Seinsvergessenheit" (Synsvergetelheid) noem. Die interessante is nou dat Heidegger in hierdie "Seinsvergessenheit" van die metafisika die eintlike grond van die nihilisme vind. "Das Sein selbst bleibt in der Metaphysik wesensnotwendig ungedacht. Die Metaphysik ist die Geschichte, in der es mit dem Sein selbst wesenhaft nichts ist: Die Metaphysik ist als solche der eigentliche Nihilismus" ${ }^{2}$ Die nihilisme is met ander woorde nie in die eerste plek geleë in die verlies van waardes, soos wat Nietzsche dit opgesom het, nie. Die nihilisme bestaan veel eerder dáárin dat die Syn hoegenaamd verstaan is in terme van ' $n$ hoogste waarde, en daartoe het die metafisika die nodige aanleiding gegee.

Die metafisiese tradisie moet verstaan word vanuit sy sentrale vraagstelling soos wat Aristoteles dit reeds geformuleer het: $t i$ to on? Wat is die synde, die synde in sy Syn? Die synde moes as synde verklaar word. Die Syn van die synde moes bepaal word. Die synde is daarom nie uitgelê in terme van die een of ander aspek daarvan of in terme van die een of ander funksie wat dit sou vervul nie, maar suiwer in sy syndheid of wese of innerlike bestemming. So verskyn die synde dan as dit wat dit self is in al sy selfstandigheid. Die merkwaardige is voorts dat die vraag na die Syn van die syndes altyd neergekom het op'n soeke na dit wat ewig en onveranderlik teenwoordig is in die syndes en wat daardeur die syndes tot syndes maak. Altyd is daar gesoek na die blywende te midde van die veranderlike, die ewige te midde van die verganklike, die substansiële te midde van die aksidentele in die verskynsels.

Deurdat die Syn in die metafisiese tradisie opgevat is as voortdurende en bestendige aanwesigheid, kon dit ook gebruik word as begrondingsprinsipe, as 'n middel tot begronding van die syndes. Hiermee kom daar 'n eienaardige karaktertrek van die metafisiese denke na vore, waarin hy volgens Heidegger sy ware motief verraai: Dit gaan nie vir hom in die eerste plek om die Syn as sodanig nie, maar eerder om die begronding van die syndes. ${ }^{3} \mathrm{Om}$ dit te bewerkstellig word die Syn gebruik. Die Syn self kom slegs ter sprake met betrekking tot die werk of die funksie wat dit verrig. Die Syn word in terme van sy funksionaliteit uitgelê, terwyl die vraag na die Syn self nie gestel word nie. Die Syn as sodanig (ontos on, on he on) is eintlik vir die metafisika geen probleem nie. Dit is eintlik die grootste vanselfsprekendheid. Problematies is eerder hoe daar midde-in die ewig-onveranderlike Synsordening ook nog wording en veranderlikheid van die syndes (gignomai, kinesis) moontlik is. Dat daar bo alle wording, verandering en beweging verhewe, 'n tydlose, onveranderlike en bestendige Syn staan, is vir die metafisika die oer-van- 
selfsprekende wat self nooit bevra word nie. "Die Urselbstverständlichkeit steht vor jeder Frage und die Frage setzt ein bei dem Wunder, dass Bewegung auch noch 'ist'. Die kinesis erweckt das Staunen, nicht aber Sein und Ewigkeit". "Die vraag na die wese van die Syn self is sekondêr tot die vraag na die relasie tussen Syn en syndes. Dit gaan steeds om die vraag na die bemiddeling tussen Syn en syndes, en in die proses bly die Syn self op die agtergrond.

Hoe dit ookal sy, die metafisika het altyd getrag om die syndes te begrond. Die grond is gevind in die bestendig aanwesige Syn van die syndes. Die Syn benodig op sy beurt egter self ' $n$ begronding sodat dit bestendige aanwesigheid kan wees. Daarom het die metafisika tradisioneel gesoek na dáárdie synde wat in 'n besondere wyse voldoen aan die eis van bestendige aanwesigheid. Dit is gevind in ' $n$ goddelike wese (theion). Die metafisika is dus benewens begronding van die syndes in die Syn (ontologie) ook nog begronding van die Syn in 'n hoogste synde (teologie). Dit is wat Heidegger bedoel wanneer hy praat van die onto-teologiese inslag van die metafisika. ${ }^{5}$ Omdat die Syn primêr vanuit die syndes bedink is, en wel as die grond of die oorsaak van die syndes, het die sprong na 'n hoogste synde (God) noodwendig geword. Hierdie hoogste synde is as Syn van die syndes die enigste waarlik synde. Alle ander syndes is alleen in ' $n$ afgeleide sin werklik. Hulle is alleen in potensiële sin werklik en nooit in die volle aktualiteit nie. Ware of volstrekte realiteit word alleen gereserveer vir dáárdie synde wat in suiwere "actualitas" bestaan sonder dat dit enige "potentia" in hom omdra: Theologisch gedacht, heisst dieses Seiende 'Gott'. Es kennt nie den Zustand der Möglichkeit, weil es in diesem etwas noch nicht wäre. In jedem Nochnicht liegt ein Mangel des Seins, sofern dieses durch Beständigkeit ausgezeichnet ist. Das höchste Seiende ist reine, stets erfüllte Verwirklichung, actus purus". ${ }^{6}$ In die suiwere aanskouing (episteme) van die hoogste synde lê die grootste vreugde en geluksaligheid van die mens opgesluit. In die bewuste konstatering van die bestaan van God kom die metafisiese strewe tot vervulling - kom die onrus van die hart en gemoed tot rus.

Met die onderskeid wat die metafisika getref het tussen die "ware" werklikheid en die "skynbare" werklikheid, is daar die nodige polariteit geskep vir die intrede van waardes binne die gesigsveld van die filosofering. Die aksiologie het onherroepelik 'n vastrapplek in die filosofie gekry. G Driscoll beskryf hierdie verwikkeling, in 'n kommentaar op Plato, soos volg: "The Idea, now absolutized, became a paradigm or model, an ideal serving as a prototype for copies. Beings possessed only derivative reality; they only approximated the actuality of the Idea. Given this situation, what was more natural than that the Ideas should be taken for values and that an attitude of comparison should arise? The distinction between 'Being-Idea' on 
the one hand, and 'being-semblance' on the other, inevitably implies a preference for the former over the latter and a corresponding evaluation ... Valuating, as a mode of thought, had made its debut" ${ }^{\prime 7}$ Die Syn, opgevat as hoogste synde (summum ens), het van nature gelei tot die opvatting van die Syn as die hoogswaardevolle (summum bonum) waarop alle syndes betrokke is, en van waaruit alles beoordeel word.

Hiermee het ons weer aangeland by die probleem van die nihilisme, en by Heidegger se stelling dat die nihilisme wesenlik berus in die "Seinsvergessenheit" van die metafisika. Die metafisika het deurdat hy die Syn bedink het in terme van bestendige aanwesigheid ('n hoogste synde en 'n hoogswaardevolle), die Syn gemaak tot iets waaroor die mens kon beskik en wat hy kon beheers in soverre as wat hy beslissend genoeg gebruik maak van sy denke. Miskien is die Syn met opset beskou as die immer teenwoordige (voorhande) hoogste synde of waarde sodat dit vir die denke beskikbaar en beheersbaar kon wees. Die Syn wat "wesentlicher ist als alle Werte und jegliches Seiende" ${ }^{\prime 8}$ het vergete geraak, en daarmee saam het die mens in ' $n$ waarderende (= subjektiverende, berekende, beheersende) grondhouding teenoor die werklikheid te staan gekom.

Wanneer Heidegger nou pleit vir 'n nuwe denkhouding, 'n denke "gegen die Werte", dan impliseer hy nie dat alles wat die mens tot "waarde" verklaar (die "kultuur", die "kuns", die "wetenskap", die "menslike waardigheid", "God") waardeloos is nie. Veel eerder kom dit daarop aan om eindelik in te sien dat juis deur die karakterisering van iets as "waarde", daardie iets van sy waardigheid beroof word. Heidegger verduidelik dit soos volg:" "Das besagt: durch die Einschätzung von etwas als Wert wird das Gewertete nur als Gegenstand für die Schätzung des Menschen zugelassen. Aber das, was etwas in seinem Sein ist, erschöpft sich nicht in seiner Gegenständigkeit, vollends dann nicht, wenn die Gegenständlichkeit den Charakter des Wertes hat. Alles Werten ist, auch wo es positiv wertet, eine Subjektivierung. Es lässt das Seiende nicht: sein, sondern das Werten lässt das Seiende lediglich als das Objekt seines Tuns - gelten. Die absonderliche Bemühung, die Objektivität der Werte zu beweisen, weiss nicht was sie tut. Wenn man vollends 'Gott' als 'den höchsten Wert' verkündet, so ist das eine Herabsetzung des Wesens Gottes. Das Denken in Werten ist hier und sonst die grösste Blasphemie, die sich dem Sein gegenüber denken lässt.

In die waarderende, subjektiverende grondhouding van die metafisika, kom sy ware wese na vore: Vóór alles staan nie'n ongeïnteresseerde, suiwer spekulatiewe "wil tot waarheid" nie, maar veel eerder ' $n$ wil tot beheersing. Hierdie wil tot beheersing het in die Moderne Periode (na die Renaissance) al duideliker na vore gekom toe die Syn van die syndes sinoniem geword het met die voorge- 
steld-wees (representasie) van objekte in die denke. Nietzsche het derhalwe net die laaste konsekwensies van die metafisiese denkingesteldheid volvoer toe hy die Syn van die syndes beskou het as die wil-die wil wat in alle voorstellings en opvattings niks anders nie as net homself bevestig, en wat daarom altyd (heimelik) "Wille zur Macht" of, nog beter, "Wille zum Willen" is. Die Syn van die syndes, dit wat aan alles ten grondslag lê, is na alles niks anders nie as die volstrekte en onbegrensde subjektiwiteit - die wil tot mag. Hierdie subjektiwiteit verhef homself tot Syn van die syndes, tot die voortdurend-aanwesige en grondliggende, deurdat hy homself "ewig wiederkehrend" wil en so in sy voortdurende aanwesigheid bevestig. So kom op 'n krasse wyse na vore dat die beheersingsdrang altyd implisiet te vinde is daar waar die Syn van die syndes opgevat word as bestendige aanwesigheid en as hoogste waarde.

Byna honderd jaar gelede het Nietzsche geskryf: "Die Zeit kommt, wo der Kampf um die Erdherrschaft geführt werden wird, - er wird im Namen philosophischer Grundlehren geführt werden". Hierdie stryd het inderdaad reeds begin, en dit word gevoer met middele waarvan Nietzsche nie eens kon droom nie. Maar word hierdie stryd in die naam van filosofiese leerstelsels gevoer? Miskien word dit ten sterkste in die naam van filosofiese stelsels gevoer daar waar van filosofie en metafisika reeds geen sprake meer is nie, maar waar die metafisiese tendens om ' $n$ laaste grond vir die werklikheid te vind tot ' $n$ uiterste gedryf word - waar 'n bestendig aanwesige Syn, 'n hoogste prinsipe, as sinvolle eindpunt of doel van die geskiedenis geponeer en die geskiedenis dan vanuit hierdie doelstelling "te lyf gegaan" en bemeester word. Vir'n geruime tyd is hierdie stryd om die uiteindelike wêreldheerskappy al aan die gang, en in hierdie stryd het die een stelsel na die ander al in die stof gebyt. Vroeër of later moes die pynlike gewaarwording kom dat alle doelstellings wat ideo-logies as die blywend-waardevolle neergelê is, spoedig in die niet verdwyn en in ongeloofwaardigheid verval. Hierdie gewaarwording is in al sy felheid deur Nietzsche uitgespreek in die stelling: God is dood. En die mens self moet die verantwoordelikheid daarvoor dra. Te lank het die mens homself in die naam van metafisika verhef tot ' $n$ absolute wese - 'n wese wat homself kan losmaak ("absolvere") van die begrensdheid van sy bestaan. Die mens het homself vervreem van sy ware wese waartoe kontingensie, historisiteit en ope (onberekenbare) toekomstigheid onherroeplik behoort. In hierdie metafisiese tendens tot selfvergoddeliking het die mens inderdaad "Mörder Gottes" geword: God is nie in sy goddelikheid gelaat wanneer hy as bestendige aanwesigheid en daarmee saam as iets beskikbaars en beheersbaars voor die mens "geplaas" word nie. God is eweneens van sy goddelikheid ontdaan wanneer hy opgevat word as hoogste waarde waarna gestreef moet word. In sy voordrag "Nietzsches Wort 
'Gott ist tot" spreek Heidegger hom soos volg uit: "Nicht das Gott für unerkennbar gehalten, nicht dass Gottes Existenz als unbeweisbar erwiesen wird, ist der härteste Schlag gegen Gott, sondern dass der für wirklich gehaltene Gott zum obersten Wert erhoben wird. Denn dieser Schlag kommt gerade nicht von den Herumstehern, die nicht an Gott glauben, sondern von den Gläubigen und deren Theologen, die vom Seiendsten alles Seienden reden, ohne je sich einfallen zu lassen, an das Sein selbst zu denken, um dabei inne zu werden, dass dieses Denken und jenes Reden, aus den Glauben gesehen, die Gottelästerung schlechthin ist ..."10

Volgens Heidegger kan die filosofie vandag nie anders nie as om "die Wahrheit jenes Wortes vom Tode Gottes ohne Illusion zu erfahren". ${ }^{11}$ Dit beteken nie dat Nietzsche gelyk gegee word nie. Nietzsche het immers self, in sy poging om die nihilisme te oorwin, aan die versoeking toegegee om aan die mensdom weer 'n hoogste waarde, 'n god voor te hou - die "Wille zur Macht". Vir Heidegger bestaan die uitweg uit die impasse van die nihilisme ten ene male nie daarin "dass irgendwann nur ein neuer Gott oder der alte neu aus dem Hinterhalt hereinstürzt" nie. ${ }^{12}$ Die nihilisme setel trouens juis daarin dat die filosofie homself nie bepaal by die Syn nie, maar telkens in die "gewaad" van die Syn 'n hoogste waarde of god optower. Hierdeur het die mens homself afgekeer van dit wat hom die wesenlikste van alles aangaan - die Syn self. Die wese van die nihilisme bestaan in die "Seinsvergessenheit" - in die metafisiese "Wille zum Wert", "Wille zur Macht" of "Wille zum Willen". Die nihilisme het as "Seinsvergessenheit" in die teenswoordige tegnokratiese bestel tot "Normalzustand" van die mensdom geword, ${ }^{13}$ en die filosofie van ons dag lewer' $n$ betekenisvolle bydrae tot die bestendiging daarvan: "Am besten zeugen dafür die ausschliesslich re-aktiven Versuche gegen den Nihilismus, die, statt auf eine Auseinandersetzung mit seinem Wesen sich einzulassen, die Restauration des Bisherigen betreiben. Sie suchen die Rettung in der Flucht, nämlich in der Flucht vor dem Einblick in die Fragwürdigkeit der metaphysischen Position des Menschen. Dieselbe Flucht drängt auch dort, wo man dem Anschein nach alle Metaphysik aufgibt und Sie durch Logistik, Soziologie und Psychologie ersetzt. Der hier vorbrechende Wille zum Wissen un dessen lenkbarer Gesamtorganisation deutet auf eine Steigerung des Willens zur Macht ..."14

En tóg, ofskoon ons al dieper en dieper in die nihilisme verstrengel raak, is daar volgens Heidegger wel 'n uitweg uit die impasse daarvan. In die woorde van Hölderline: "Wo aber Gefahr ist wächst das Rettende auch". ${ }^{15}$ Daar is redding moontlik, mits hierdie redding nie gesien word as 'n menslike prestasie, as iets wat die mens uitsluitlik vir homself by wyse van hernude inspanning kan bewerk nie. Te lank het die mens hom blind gestaar teen sy eie ver- 
moëns en daarmee die dimensie van die Heil, die helende genade, uit die oog verloor. "Vielleicht besteht das Auszeichnende dieses Weltalters in der Verschlossenheit der Dimension des Heilen. Vielleicht is dies das einzige Unheil". ${ }^{16}$ Miskien wil die nihilisme ons bring tot ' $n$ inkeer in die "Armut der Existenz des homo humanus". ${ }^{17}$

Denke in die skaduwee van die nihilisme, denke vanuit die armoede van die eksistensie, is denke wat homself nie meer verstaan as voortsetting van die metafisiese tradisie met al sy berekendheid en pretensie nie. Dit is denke wat vanuit 'n wesenlike ervaring van die nihilisme opgebou het om die "Niks" te beskou as bloot net die vervlugtiging (negasie) van hierdie of daardie hoogste waarde, of as vreemde bedreiging (wederstrewigheid) wat ten alle koste te bowe gekom moet word in 'n herbevestiging van 'n bepaalde synde as hoogste synde. Die Niks moet veel eerder bedink word as behorende tot die Syn self. So word die Niks ervaar as die "Schleier des Seins"18 "als jener Schleier, der uns jeweils das Sein zeight, indem er es uns entzieht, der somit den gierigen Ausgriff auf ein beständig anwesendes und verfügbares Sein, als den Grund alles Seinden unmöglich macht" ${ }^{19}$ Word die Niks bedink as toebehorend tot die Syn, dan toon die Syn homself in sy waarheid as die "unverfügbare Ereignis" - as oergebeure waaroor geen mens beskik en waaroor geen mens enige mag het nie.

Hieruit is duidelik dat alle menslike pogings om die nihilisme te "oorwin" vir Heidegger twyfelagtig skyn te wees. Die nihilisme behoort soos die Niks self tot die wese van die Syn. En omdat die mens nie beskik oor die Synsgebeure nie, lê dit ook nie binne sy vermoë om die Niks "uit te ban" en daarmee die nihilisme te besweer nie. Dit is die lotsvoorreg van die mens om "Platzhalter des Nichts" of "Hineingehaltenheit in das Nichts" ${ }^{20}$ te wees. Só gesien is die nihilisme geen onheil wat die mens oor homself gebring het en wat hyself weer te bowe moet kom nie. Die nihilisme is aan die mens toeberei. Dit is oor hom beskik. Dit is nie toe te skryf aan een of ander versuim of tekortkoming van die mens nie. ${ }^{21}$ Die nihilisme is ' $n$ bestiering ("Geschick") van die Syn sélf - 'n epog in die "Geschichte des Seins".

(Hier moet terloops daarop gewys word dat die uitdrukking "Geschichte des Seins" nie daarop dui dat die Syn eers ewig, absoluut, "an sich" daar is, en dan nog daarnaas ook 'n geskiedenis het nie. Die Syn word nêrens deur Heidegger verselfstandig bo geskiedenis en tyd nie. Syn en geskiedenis, Syn en tyd, hoort onherroeplik "bymekaar", in so 'n mate dat die Syn verstaan moet word as "geskieding" van die geskiedenis en as "Zeitigung der Zeit". .)

Die insig dat die wysbegeerte nou al eeue lank in "Seinsvergessenheit" gewikkel is, gekoppel aan die insig dat hierdie "Seinsverges- 
senheit" nie op 'n menslike vergissing berus nie maar op die "uitbly" van die Syn sélf, open die moontlikheid tot 'n nuwe ervaring van die Syn - dit naamlik, dat die Syn tot openbaring kom in soverre as wat hy hom verberg. Anders gestel: Ons kan die Syn net op 'n negatiewe wyse ervaar in die medium van sy verberging. Geen onmiddellike ervaring van die Syn is vir ons moontlik nie. Ons ken die Syn nie in sigself nie, maar slegs in die mate waarin dit tot openbaring kom in, en sig verberg agter die syndes wat dit nie is nie. Die Syn is die Gans Andere dan die syndes. Dit is geen synde nie - dit is die niesynde, die "Niks" in terme van die syndes. ${ }^{23}$

Ons het tot dusver kon vasstel dat Heidegger die nihilisme radikaler as enigiemand anders verstaan vanuit die fundamentele Synsvergetelheid soos wat dit op dreef gekom het sedert Plato se uitleg van die Syn as Idee. Ons het voorts kon vasstel dat Heidegger nie by hierdie bloot historiese ervaring bly staan het nie, maar dat hy die histories-begrypbare Synsvergetelheid transendeer en dit as ' $n$ wesenlike "Äusserung" (uiting) van die Syn self verstaan: as uiting van die "Ab-gründigkeit" van die Synsgeskiedenis. Via 'n wesenlike ervaring van die nihilisme kom Heidegger tot 'n inkeer in die wese (verbaal verstaan!) van die Syn as "Ab-wesen" en "Ab-grund" - tot die bevinding dus dat die Syn nie ewig en absoluut daar is nie, maar slegs as "Ereignis", "Geschick", "Entbergung und Verbergung", "Zeit" en 'Geschichte". ${ }^{24}$

Hieruit blyk baie duidelik die hermeneutiese inslag van Heidegger se filosofie. Die metafisiese poging om te kom tot' $n$ wesensbepaling van die Syn "an Sich" word laat vaar ten gunste van 'n ervaring van die Syn via die eksplisitering van die wyse waarop die mens tot nog toe die Syn ervaar het. Die Syn kan nooit los van die mens gesien word nie. Die mens is immers "Da-sein" as die daarwees van die Syn of die plek waar die Syn daar is. ${ }^{25}$ In "Sein und Zeit" skryf Heidegger ${ }^{26}$ : "Das 'Wesen' das Daseins liegt in seiner Existenz". Hierdie stelling mag nie bloot antropologies (erger nog: eties) verstaan word nie. Met hierdie stelling bedoel Heidegger niks meer nie en niks minder nie as dat die mens hom oral en altyd reeds bevind in die "Offenheit des Seins", of, soos wat hy dit ook graag stel, in die "Wahrheit des Seins". ${ }^{27}$ Die mens is altyd reeds geworpe in een of ander "Seinsverständnis" en daarin kom die fundamentele samehorigheid van Syn en mens tot uitdrukking. "Nur solange Dasein ist, gibt es Sein". ${ }^{28}$

Die feit dat die mens wesenlik eksistensie is en dus in die Waarheid van die Syn staan, beteken nie dat die Syn volkome in die mens opgaan nie: "Von der recht gedachten 'Existenz' her lässt sich das 'Wesen' das Daseins denken, is dessen Offenheit das Sein selbst sich bekundet und verbirgt, gewährt und entzieht, ohne dass sich diese Wahrheit des Seins in Dasein erschöpft oder gar mit ihm sich in eins setzen lässt nach der Art des metaphysischen Satzes: alle Objektivi- 
tät ist als solche Subjektivität". ${ }^{29}$ Miskien herken mens hier iets van die sg "relatio transcendentalis" van die middeleeuse wysbegeerte ${ }^{30}$ - 'n relasie waarin beide terme nie bestaan buite om die realsie waarin hulle staan nie. ljsseling merk tereg op dat daar by Heidegger nog iets meer is. Die Syn het naamlik 'n sekere "prioriteit". Omdat die Syn wesenlik "Seinsgeschichte" is, en die menslike denke (Synsverstaan) nooit meer kan wees as 'n vervlietende oogwink of epog in die voortstuwende Synsgeskiedenis nie, bly die Syn steeds die " $\mathrm{Zu}$ denkende", die gewende wat as opgawe steeds bly gee. Ten spyte van die fundamentele samehorigheid is daar 'n onagterhaalbare "Differenz" tussen Syn en denke.

Wie die hele gedagtegang van Heidegger, soos wat dit tot hiertoe baie kort en hopeloos ontoereikend ontplooi is, meevoltrek, kan nie anders nie as om saam met hom daarvan uit te gaan dat die Syn as Synsgeskiedenis nie eenvoudig iets identies in homself is nie. Veel eerder moet aanvaar word dat die Syn, ten spyte van 'n oorspronklike "Selbigkeit" in die geheel van die Synsgeskiedenis, "jeweils in den verschiedenen Epochen seines Geschicks anderes sagt". ${ }^{31}$ Dit impliseer die volgende: Die Syn as Synsgeskiedenis openbaar homself eerder deur "Ausbleiben" as deur "Anwesen", en, die wese van die denke is eerder geleë in 'n "Aussein-auf" 32 as in 'n "Begreifen".

Ten slotte: Ons besinning rondom die denke van Heidegger was nie "krities", wanneer onder krities die opspoor van allerlei denkfoute verstaan word nie. Hierdie besinning is, soos wat reeds in die inleidingsparagraaf gesuggereer is, gemotiveer vanuit die vraag na hoe die filosofie homself teenswoordig kan en moet verstaan. Waarin setel die bestaansreg van die filosofie in die lig van (beter: in die skaduwee van) die nihilisme soos wat dit in ons tyd kenbaar geword het? 'n Ontmoeting met die denke van Martin Heidegger lewer hier vrugbare perspektiewe wat ons soos volg kan opsom:

Die filosofie het, sterker as ooit tevore, die taak om die mens los te ruk uit sy gevangenheid en bevangenheid in sy wêreld - 'n bevangenheid wat veral daar heers waar die mens hom "mondig" voel en sy wêreld voorhou as die enigste wêreld. Hierdie "mondige bevangenheid" verdwyn eers wanneer ons ons bewustelik "verplaas"' in 'n pluraliteit van wêrelde waarin ons altyd reeds staan. Die filosofie moet die mens "beweeg" tot ' $n$ bewuste staan (be-staan) in die geskiedenis van opeenvolgende wêrelde.

Die filosofie is geen passielose, ongeïnteresseerde en werklikheidsvreemde bedryf nie. Omdat die filosofie die mens beweeg tot 'n bewuste staan in die geskiedenis, waarin hy sy wêreld sien as maar een van vele moontlikhede van die omvattende geheel, open die filosofie aan die mens die moontlikheid om tot'n 
bevrydende beslissing te kom aangaande die sin van sy wêreld. Die filosofie maak'n sinvolle mensbestaan moontlik - weliswaar nie meer langs die weg van "metafisiese" abstraksie nie, maar langs die weg van 'n konkrete "metahistoriese" besinning, " besinning waarin die heersende historiese wêreld "opgeweeg" word teen ander wêreld-moontlikhede. In hierdie besinning, wat altyd ' $n$ Ja en 'n Nee teenoor die gegewe historiese wêreld impliseer, lê die voorwaarde vir die mens se vrye gebondenheid aan die tydvak waarin hy staan. So gesien is die filosofie daardie beslissende gebeure waarin die mens kom tot 'n vrye (=krities, transenderende) aanvaarding van die gegewe historiese wêreld as lotsbeskikking. In die filosofie word die mens vry tot ' $n$ bewuste en verantwoorde deelhebbing aan die geskiedenis waarin hy staan. In die filosofie word die mens vry vir sy eie historiese vryheid - 'n vryheid wat niks meer in gemeen het met 'n "geschichtslose" bevryding of "emansipasie" soos wat dit in die naam van 'n sogenaamd tydlose "Etiek" of "Moraliteit" aan die mens verkondig word nie.

Wanneer die menslike vryheid verstaan word as historiese ("geschichtliche") vryheid, en wanneer die filosofie gesien word as die bewustheid van hierdie vryheid, dan spreek dit vanself dat die filosofie niks minder is nie as die voltrekking van hierdie vryheid self. Sonder om aan enigiets diensbaar, of vir enige doeleinde bruikbaar te wees, behoort die filosofie onlosmaaklik tot die historisiteit van ons menslike bestaan. Die "bestaansreg" van die filosofie setel in sy eie noodwendigheid. As voltrekking van die menslike vryheid voltrek die filosofie hom suiwer om wille van sy eie voltrekking. Alleen wanneer ' $n$ mens dit verstaan, verstaan jy die weg van die vryheid en daarmee saam die weg van die filosofie.

1. Nietzsche (Bd II), p 342 ev

2. Ibid, p 350.

3. Vgl Einführung in die Metaphysik, p 65; Holzwege, p 306; Wegmarken, p 195.

4. M Müller, Existenzphilosophie im geistigen Leben der Gegenwart, $\mathrm{p} 226$.

5. Identität und Differenz, p 52.

6. Nietzsche Bd. II, $\mathrm{p} 348$.

7. G Driscoll, "Heidegger - a response to nihilism" in Philosophy Today, Vol II (1967) no 1, p 19. Vgl ook M Heidegger, Einführung in die Metaphysik.

8. Wegmarken, $\mathrm{p} 182$.

9. Ibid p 179.

10. Holzwege, p 239 e v

11. Ibid, $\mathrm{p} 235$.

12. Ibid, p 249. Vgl Nietzsche Bd II, p 340 .

13. Wegmarken, $\mathrm{p} 220$.

14. Ibid

15. Die Technik und die Kehre, p 28.

16. Wegmarken, p 182.

17. Ibid 
18. Wegmarken, $\mathrm{p} 107$.

19. O Pöggeler, "Metaphysik und Seinstopik bei Heidegger" in Philosophisches Jahrbuch, Vol 70 (1962/3) no 1, p 128.

20. Wegmarken, pp 12 en 15.

21. Die "Seinsvergessenheit" kan nie "antropologies" verstaan word soos wat $H$ in Sein und Zeit nog geneigd was om te argumenteer nie. Vgl Wegmarken, p 243; Holzwege, pp 244 en 336; Vom Wesen der Wahrheit, pp 17-22.

22. Vgl veral "Zeit und Sein" in Zur Sache des Denkens, p 1-25.

23. Wegmarken, pp 246-248.

24. Vgl Der Satz vom Grund, pp 110, 120-122; Wegmarken, p 193.

25. Wegmarken, p 202.

26. $\mathrm{p} 42$.

27. Wegmarken, p 203.

28. Sein und Zeit, p 212.

29. Wegmarken, p 203.

30. Vgl S Ijsseling, Heidegger. Denken en Danken, Geven en Zijn, p 58.

31. Der Satz vom Grund, p 110.

32. Die term word hier wellig in ' $n$ ander sin gebruik as waarin $\mathrm{H}$ dit nog in "Sein und Zeit"' gebruik het (Vgl daar pp 195 en 262).

33. $\mathrm{Vgl}$ in hierdie verband $\mathrm{M}$ Müller, a w, p $250 \mathrm{e} \mathrm{v}$. 